\title{
La visión de la mujer y la feminidad en los artículos de María Luz Morales publicados en 'La Vanguardia' (1921-1936)
}

\section{The Vision of Women and Femininity in María Luz Morales' Articles Published in 'La Vanguardia' (1921-1936)}

Francesc Salgado de Dios

Universitat Pompeu Fabra (España)

Esther Lázaro

Universitat Autònoma de Barcelona (España)

Desde que en 1921 la firma de María Luz Morales irrumpe en el diario La Vanguardia, del que llegará a ser directora durante unos meses en 1936, aparece como una de las primeras mujeres que trabajan en la redacción de un periódico en España. En estos primeros años, publica en el diario barcelonés diferentes tipos de artículos. Entre ellos, y desde su mismo debut, destacan algunos dedicados a la "condición femenina", en los que se vislumbra un esfuerzo para que la mujer no se recluya en el entorno doméstico y acceda libre y habitualmente a la cultura, a la educación, al mundo laboral y, con todo ello, a la libertad de expresión.

Esta posición se complementa con otra que tiene que ver con la maternidad, para la que reclama una serie de valores que considera femeninos: la ternura, el amor y la imaginación. Morales reclama una
When María Luz Morales's byline appeared in 1921 in the newspaper La Vanguardia, of which she would be the editor for a few months in 1936, she became one of the first women to work in the newsroom of a newspaper in Spain. In those first years, she published different types of articles in La Vanguardia. From the very first, some articles dealing with the "female condition" stand out. In these, there is a discernible appeal for women not to enclose themselves in the domestic environment and to have free and regular access to culture, to education, to the workplace and, consequently, to freedom of expression.

This stance is complemented by another related to motherhood, for which she claims a series of values that she considers feminine: tenderness, love, and imagination. Morales appeals for a childhood without the rigor of obe- 
infancia sin el rigor de la obediencia y la disciplina, armada más bien de creatividad y cultura. En conjunto, la periodista defiende en sus artículos una feminidad activa y culta, independiente, conservadora y con un fuerte activismo social que, sin embargo, rechazaba las etiquetas. La primera, ser considerada feminista.

Palabras clave: La Vanguardia, María Luz Morales, mujeres periodistas, feminismo. dience and discipline, built rather on creativity and culture. On the whole, the journalist defends in her articles a femininity which is active and cultured, independent, conservative and with a strong social activism that nevertheless rejects labels. The first: to be considered a feminist.

Keywords: La Vanguardia, María Luz Morales, women journalists, feminism.

4 1 estudio sobre las ideas de María Luz Morales apenas se ha iniciado. Fue señalada a finales del franquismo como una precursora en el periodismo y como una profesional adelantada a su tiempo (Rodrigo, 1979: 151-157), y ese punto de vista laudatorio se repitió en varios homenajes que se le ofrecieron en la Transición y cuando falleció, en 1980. Sin embargo, el entorno académico ha sido remiso a estudiar su pensamiento y su trabajo hasta hace poco tiempo. Una primera biografía ha allanado el camino (Cabré, 2017), así como dos trabajos especialmente valiosos, el primero sobre Paulino Masip, pero con referencias a María Luz Morales como la directora de La Vanguardia que le precedió (Pericay, 2010), y otro que describe el trabajo de Morales en tanto que traductora y adaptadora de libros infantiles (Julio, 2017). ${ }^{1}$ También cabe destacar un preciso perfil periodístico de la autora a cargo de Jaume Fabre (2017: 71-80) y un trabajo sobre las críticas cinematográficas que desarrolla en La Vanguardia (Servén: 2013).

Con este primer material quedan centradas las grandes áreas de interés de una vida compleja, variada y especialmente discreta de una mujer que fue calificada como "la gran señora de nuestra prensa" (Tarín, 1973: 5). Si el autor de esta expresión se refería a toda una vida de trabajo en la promoción de la literatura, el teatro y la cultura, no le faltaba razón. Pero el conocimiento que tenemos sobre ella no es más que unos trazos de quién fue realmente María Luz Morales más allá de la percepción pública de extrema pulcritud y reserva personal que escogió para sí misma (Rodrigo, 1979: 152-153).

Poco a poco comprendemos la trascendencia del vacío que rodea a una pionera del periodismo cultural que dedicó más de cincuenta años a la profesión.

1 Precisamente Teresa Julio anuncia dos nuevos trabajos en preparación sobre la labor de María Luz Morales en la editorial Araluce. 
María Luz Morales nació con la debacle del 98; empezó a trabajar justo después del desastre de Annual en la guerra del Rift, en el actual Marruecos; fue la primera mujer que dirigió un diario de alcance nacional, La Vanguardia, unos meses entre 1936-1937; y pasó la guerra civil en el periódico, en la que era su redacción desde 1923. No se exilió tras la guerra, aunque — quizás sin saberlo— formaba parte de los derrotados. Fue encarcelada y procesada tras la guerra civil, además de apartada del periodismo hasta 1948, un periodo que se alarga a 1961 si nos referimos a su reingreso oficial en la Asociación de la Prensa de Barcelona.

Sobre su vida, la falta de información que la rodea es patente desde la misma fecha de nacimiento, atribuida sin precisión a varios momentos distintos. Nosotros tomaremos como buena la que aparece en su DNI, el 23 de abril de 1898, según una fotocopia del mismo que consta en el expediente personal que se encuentra en el archivo del Col-legi de Periodistes de Barcelona. Se han ofrecido otras fechas que remiten casi a una década antes. Teresa Julio (2017: 56) da como buena la del 23 de abril de 1890. Por su parte, Má Ángeles Cabré (2017: 17), autora de la biografía, sitúa el nacimiento todavía 16 meses antes, el 1 de enero de $1889 .{ }^{2}$

La bibliografía está de acuerdo en que la escritora nació en La Coruña y a los pocos años, siendo una niña, emigró con su familia primero a Granada y luego a Barcelona. De familia acomodada, formada por militares y altos funcionarios públicos, se instaló en la ciudad Condal y estudió en una institución que indicaba cuáles eran las inquietudes culturales de la muchacha, el Instituto de Cultura y Biblioteca para la Mujer Francesca Bonnemaison, en la sede que mantuvo en la primera etapa, en la calle Elisabets, antes de que en 1922 se trasladara a la calle Sant Pere Més Baix debido a la alta demanda. Se trataba de un centro de capacitación profesional dedicado en exclusiva a la mujer en el que era posible revertir, a principios del siglo XX, las diferencias de formación de las mujeres respecto a los hombres. Allí cursó Morales estudios de Pedagogía, que le proporcionaron una visión renovadora de los espacios educativos sobre los que, como veremos, escribió profusamente. La participación en estos cursos le dio también una visión solidaria y de conjunto de la situación de la mujer, sobre la que reflexionó a lo largo de su carrera profesional desde diferentes puntos de vista, siempre alrededor de un presupuesto central: el derecho y la necesidad de la cultura. Esta preocupación le haría participar en diversas iniciativas públicas en defensa de la mujer.

En otoño de 1920 empezó a trabajar como "cronista", es decir, redactora, en la revista El Hogar y la Moda tras ganar un concurso que la propia revista convocó para

2 Sin embargo, ninguna de las dos autoras especifica el origen de esos datos. Julio afirma obtenerlo de la partida de defunción, pero no indica la localización de dicho documento. Todavía existen más datos incongruentes: en el expediente judicial (número 139038) de la causa que se instruyó contra María Luz Morales en 1940 como represalia por haber dirigido La Vanguardia durante unos meses, se dice que la encausada tenía durante dicha instrucción 45 años. Si en 1940 tenía 45 años, el año de nacimiento sería 1895. También Jaume Fabre (2017: 79) hace una interesante referencia a las incertidumbres que rodean la fecha de nacimiento, y, por tanto, la edad, de María Luz Morales. 
sustituir "por enfermedad" a la mujer que hasta entonces ejercía como tal, Concepción P. Mariné ("Revista...", 1920). Morales firmaría en la revista un artículo en la página 3, y su trabajo consistiría, además, en organizar el espacio de los colaboradores - articulistas e ilustradores - y la sección del consultorio, Todos a Todos, como única redactora de mesa de la revista. El Hogar y la Moda aparecía tres veces al mes. Fue fundada en 1910 y tenía 18 páginas, muchas de ellas dedicadas a la publicidad. Abundaban los artículos repletos de consejos domésticos, los figurines de moda y las recomendaciones de salud, e iba dirigida claramente a mujeres de clase media y alta. La vocación comercial de la publicación incluía sorteos, promociones y ofrecía nuevos productos editoriales como enciclopedias o libros de Historia. El Hogar y la Moda llegó a alcanzar una difusión en la época de hasta 100.000 ejemplares de tirada (Cabré, 2017: 50). Segura y Selva (1984: 127-130) catalogan la revista como "familiar o doméstica", lejos de las que "analizan la condición de la mujer".

Sin duda, este trabajo propició el debut de Morales en La Vanguardia, que acaeció al siguiente verano, en julio de $1921 .^{3}$ Era una época en la que algunas mujeres pudieron acceder a determinadas redacciones porque se había instalado una cierta tendencia en incluir contenidos "femeninos" en la prensa catalana (Altés, 2007: 38-44). Con todo, llama la atención que María Luz Morales no debutase en el matutino barcelonés dentro de una sección femenina, sino en la página de artículos nobles del diario. Su aparición se da en un contexto de renovación del conjunto de colaboradores que impulsó Agustí Calvet, Gaziel, a partir de 1920, cuando fue nombrado director efectivo del diario para competir con el resto de la prensa de la ciudad (Guillamet, 1994: 94-100). Sin embargo, el mismo Gaziel (1994: 108-112) ha descrito las muchas dificultades que tuvo para renovar poco a poco la nómina de colaboradores y acercar nuevas firmas a un diario que pretendía ser más moderno, informativo y cercano editorialmente al catalanismo moderado, un objetivo que tenía que conciliar con la mentalidad muy tradicional y conservadora de Ramón Godó Lallana, su propietario.

Pese a todo, La Vanguardia consolidó durante los años veinte su modelo de éxito. Ya en 1918 había alcanzado una difusión de 100.000 ejemplares diarios, el doble del segundo periódico de la ciudad, Las Noticias (Gómez, 1992: 124). Gracias a la incorporación intensiva de la publicidad y diferentes inversiones que aumentaron su capacidad de producción, buena parte de la prensa editada en Catalunya dio un salto espectacular en su capacidad de producción y difusión. En este proceso destacó especialmente La Vanguardia, famoso bajo el empuje de Gaziel por la ambición comercial y el impulso tecnológico de un diario que pretendió sobre todo ser un buen negocio a través de la eficacia informativa (Llanas, 1998: 96-97). Cuando Carlos Godó Valls sucedió a su padre en 1931 y Gaziel fue nombrado por fin director único, en 1934, el diario ya no solo era el más rentable de España, sino uno de los mejores del continente (Huertas, 2006: 82).

3 La primera columna apareció el día 21 de julio de 1921 y lleva por título "Las hadas vuelven". Ella misma evoca este primer trabajo en otro artículo, "Una varita de virtud...., aparecido en el mismo diario unos años después, el 1 de enero de 1936. 
El papel de María Luz Morales en este proyecto, una joven de veintitrés años cuando debutó en La Vanguardia, tenía que ver con escribir para el público femenino en la página de opinión, Artículos y Comentarios'. Sus textos iban claramente dirigidos a las mujeres y se tiñeron en seguida de reflexiones asociadas al teatro, la educación y la literatura, con los que marcó una destacada impronta personal y a la vez una distancia clara con el trabajo que llevaba a cabo a su vez en El Hogar y la Moda, más técnico y doméstico. En la revista, la reflexión sobre la mujer quedaba en manos de alguno de los colaboradores masculinos, no en las firmas femeninas. Son precisamente los artículos publicados en esta sección de La Vanguardia los que permiten extraer la visión del modelo de mujer que Morales defendió.

No se quedó aquí su dedicación en el periódico barcelonés. En 1923 comenzó una colaboración cinematográfica bajo el seudónimo de Felipe Centeno, de aires galdosianos, en la que comentaba los estrenos y la actualidad cinematográfica, toda una novedad en su momento. A raíz de esta sección, que llevaba por nombre Vida Cinematográfica y ocupaba una página entera del periódico, María Luz Morales entró finalmente en la plantilla de La Vanguardia. Se ocupó de la crítica cinematográfica desde 1923 hasta 1933. Unos meses más tarde pasó a encargarse de las críticas sobre teatro, su auténtica pasión. De hecho, de joven quiso ser actriz, tal como explica ella misma en una entrevista (Favà, 1975: 81); se encargó de algunas adaptaciones y versiones al castellano de obras de teatro infantil catalán; escribió, a su vez, piezas escénicas para niños, representadas por niños; e incluso llegó a estrenar una comedia en el Teatro Arriaga de Bilbao, Romance de media noche, en coautoría con su amiga y también escritora Elisabeth Mulder, en 1936.

Su dedicación como periodista todavía creció más, puesto que entre 1926 y 1931 se encargó, ahora sí, de una columna semanal de asuntos femeninos en el diario El Sol, de Madrid. La sección llevaba por título La mujer, el niño y el hogar. Todo ello aderezado con las diferentes actividades culturales que mantuvo durante toda su vida. En primer lugar, la adaptación de libros para el público infantil, en especial en la editorial Araluce, además de varias obras de ficción y apariciones ocasionales en otras publicaciones. También las numerosas conferencias que ofreció en escenarios como la Universidad de Barcelona, el Ateneu Barcelonès, el Círculo Ecuestre o el Lyceum Club de Barcelona, entre otros, en su mayoría de temática literaria y femenina, en la línea de los artículos revisados en este trabajo. Destaca en esta intensa actividad profesional la colaboración con la empresa Paramount Pictures, cuya filial en España recurrió a ella para adaptar los textos y las traducciones de algunas de las películas que distribuía.

María Luz Morales, como puede constatarse, trabajó durante el periodo estudiado con un entusiasmo y una obstinación destacables. Josep María Casasús (1988: 81) la sitúa dentro del periodismo cultural, mientras que Elvira Altés $(2007: 63,66)$ lo hace entre las primeras mujeres que se dedican profesionalmente al periodismo, la tercera en Catalunya. Su vocación periodística y, en general, el empeño que imprimió a todas sus actividades no perdieron intensidad, y todavía se necesita que un estudio pormenorizado describa su trabajo completo en la prensa entre 1921 y 1977, más de cincuenta años de dedicación al periodismo cultural. 


\section{METODOLOGÍA Y PRIMEROS RESULTADOS}

La recopilación de artículos para este periodo de estudio se realizó a través de la Hemeroteca digital de La Vanguardia. Las diferentes búsquedas cruzadas que se realizaron con distintas firmas y acrónimos atribuibles a María Luz Morales dieron un resultado total de 573 artículos publicados entre los años 1921 y 1936. Entre estos, 115 resultaron ser críticas teatrales, además de otros 398 comentarios cinematográficos firmados con el pseudónimo Felipe Centeno. ${ }^{4}$

Los sesenta artículos restantes son los que centran el objeto de estudio de este trabajo, no solo porque expresan de forma más directa su pensamiento, sino porque, como se ha dicho, aparecían publicados en las páginas más nobles del diario, entre la 5 y la 6 , las que siguen a las portadas publicitarias que en aquella época empezó a utilizar La Vanguardia, las mismas que a partir de 1929 se imprimieron en huecograbado. La página 5 (o en ocasiones la 7) era, por tanto, la primera página no comercial del diario y recogía normalmente dos o tres artículos firmados por importantes figuras del periódico, entre ellas el mismo director. Los artículos solían tener entre 1.300 y 1.500 palabras de extensión y se distribuían en las cuatro columnas de la página.

La distribución temporal de estos trabajos resulta llamativa. María Luz Morales apenas escribe uno o dos artículos anuales en los primeros tiempos, hasta que en 1927 publica cinco y en 1928, seis. Después decae de nuevo, y publica dos en 1930 y otros dos en 1931, para pasar de nuevo a cinco en 1932. Al año siguiente se produce el gran salto, pues, de forma extraordinaria, publica hasta tres reportajes por entregas: el primero sobre un viaje a Galicia, en julio; el segundo sobre las elecciones celebradas en Andorra, en agosto; y el tercero, uno de los más célebres, en octubre de 1933, una serie de tres capítulos dedicados al voto femenino en las elecciones legislativas de 1933, justo cuando iba a estrenarse el derecho al voto de la mujer. Ese año se salda con diecisiete piezas publicadas.

El resto de años del periodo de estudio, entre 1934 y 1936, Morales publica cuatro o cinco artículos por año, una cifra que refleja el cambio de estatus que había protagonizado dentro de la redacción pero que en sí misma no resulta extraordinaria. Una vez estalla la Guerra Civil y la Generalitat incauta La Vanguardia, en agosto de 1936, será nombrada directora del periódico y su dedicación dentro del diario cambia por completo, ${ }^{5}$ por lo que prácticamente no publica ningún artículo en la página de opinión, Artículos y Comentarios, razón por la que el periodo de estudio de este artículo acaba en este momento aunque ella siguiera con funciones asignadas dentro de la redacción. El funcionamiento del

4 Ambas cantidades son provisionales ya que el estudio de la crítica cinematográfica o teatral de Morales no constituye un objetivo de este trabajo. Se ofrecen solo a título orientativo.

5 Se mantuvo como directora entre julio de 1936 y febrero de 1937, cuando fue sustituida por Paulino Masip. Siempre explicó que había aceptado el cargo por la gravedad del momento, para mantener los puestos de trabajo, sin admitir un incremento de sueldo y, sobre todo, con la condición de que las labores editoriales recayeran en las personas que estaban acostumbradas a ellas (Sariol, 1977: 132-133). 
rotativo se vería notablemente alterado con la guerra, el control político y las carencias de papel, y, por tanto, hemos preferido estudiar la obra de María Luz Morales hasta julio de 1936, es decir, mientras se desarrolló con normalidad.

Cabe advertir, sin embargo, que no todos los artículos entre los sesenta seleccionados tuvieron interés para nuestro estudio. Una vez localizados, se aplica el enfoque del Análisis Crítico del Discurso (ACD) para comprobar si los argumentos de los artículos analizados incluyen alusiones significativas sobre el papel de la mujer. Dicho análisis es una adaptación de las técnicas propuestas por Van Dijk (1996) y Wodak y Meyer (2003). En un análisis de primer nivel se extraen diversas proposiciones relevantes que son la base sobre la que se sustentará el análisis.

En concreto, una vez leídos y catalogados, nos resultaron útiles una parte de esos sesenta artículos, aquellos que exponían referencias claras al papel que propugna María Luz Morales para la mujer en la cambiante sociedad de principios del siglo XX. Publicó buena parte de estos artículos bajo el epígrafe Glosas femeninas o Temas femeninos, de forma que se da a entender que la literatura y la cultura siempre estuvieron condicionadas por su forma de entender la feminidad.

\section{UNA MODERNIDAD CONSERVADORA}

El primer indicio de su preocupación por la feminidad aparece en su tercer trabajo, en octubre de 1921, cuando glosa en un artículo el papel de la mujer en las guerras. Todavía bajo el impacto del desastre de Annual y de la guerra que sigue activa en Marruecos, dedica un artículo a las enfermeras que sirven en los hospitales de campaña y no les ahorra elogios:

Silenciosas, anónimas, dejando atrás familia, lujo, ociosidad, amor... cruzan el mar nuestras mujeres. Van también a luchar allá abajo y son sus enemigos el Dolor y la Muerte. Mas no les faltan armas para vencer. Llevan consigo la abnegación, la piedad, la ternura, la palabra amable, espiritual y persuasiva, la dulce sonrisa... (...) y aún, por añadidura, algo más sólido y no menos preciso: la energía, la cultura, la ciencia, la organización (Morales, 1921).

Se refiere a las enfermeras al estilo de las que enrolara miss Florencia Nightingale, la creadora de la Cruz Roja durante la guerra de Crimea, a mediados del siglo XIX. Un tipo de mujer como las que han de leerle, de clase acomodada o emergente, de las que reclama la abnegación, pero, sobre todo, su ciencia. Un "tipo ideal femenino" en el que puedan "hermanarse la gracia, la inteligencia y el heroísmo" (Morales, 1921).

Esta primera referencia a la feminidad en la obra de Morales en La Vanguardia se mantendrá vigente: reivindica un talante femenino que no rompe con las características domésticas tradicionales, es decir, de tono conservador, pero le añade apuntes reivindicativos referidos a la cultura y al conocimiento, como si quisiera llamar la atención sobre la eficacia de las mujeres.

Si de las enfermeras destaca la ciencia y la organización, de las "maestritas", será la innovación pedagógica. A ellas les solicita que los cuentos infantiles entren en las aulas, ya que "la verdadera magia del cuento reside en la narración 
oral del mismo. Hay en la voz humana algo que va directamente al alma humana; que es fuente de emoción y de gozo, que establece viva corriente de simpatía entre el que habla y el que escucha" (Morales, 1922). No todo es instrucción y repaso, la educación no se reduce a cantar en el aula las tablas de multiplicar. Morales reclama que se alimente a los niños con la imaginación y con el placer que subyace en el conocimiento. Y se muestra fiel a la pasión por la cultura que siempre experimentó ella misma, además de tener presente su propia devoción como traductora y adaptadora de textos infantiles.

En la literatura universal, también reivindica un lugar para las mujeres. En el centenario de la muerte de Molière, recomienda a este autor pese a que no haya tratado muy bien a las mujeres en sus comedias, unos personajes que suele presentar como seres interesados o incluso como marionetas (Morales, 1923). La mujer en la literatura sufre el síndrome del romanticismo, explica Morales, ya que fue denostada durante siglos hasta que se la encumbró por primera vez en el Romanticismo, hasta el punto de que se la convirtió en una semidiosa irreal y evanescente. No es de extrañar — concluye al repasar en otro artículo la nefasta influencia que tuvieron un puñado de mujeres reales en otro grande de la literatura, Lord Byron- que su papel sea siempre tan secundario (Morales, 1924).

Un tiempo más tarde, ya en 1927, vuelve sobre la educación y recomienda a Rabindranath Tagore como el primer gran filósofo que realmente comprende a las mujeres, como se deduce, precisamente, por la atención que han dedicado al poeta hindú diversas intelectuales como Gabriela Mistral o Zenobia Camprubí, esposa de Juan Ramón Jiménez. Por primera vez, en los comentarios de María Luz Morales aparecen literatas y escritoras como protagonistas, más allá del autor que los origina. Morales precisa que estas estudiosas destacan la capacidad de Tagore para entender y glosar las virtudes implícitas en la educación de los niños, en la pedagogía: amor, comprensión y sensibilidad.

\footnotetext{
El alma del niño es una ardiente aspiración hacia la vida, hacia la naturaleza, de la que cada día se le arranca, como de una madre, para encerrarle en la escuela. Y el saber que esta escuela, no es, en muchos casos, sino "un aparato de disciplina, que rechaza el tener en cuenta al individuo; una oficina destinada a manufacturar productos uniformes", donde la educación más importante a que está destinado el niño queda descuidada; donde se le priva de la tierra para enseñarle geografía; donde se le quita el lenguaje para iniciarle en la gramática, donde se le hace estudiar botánica en las páginas de un libro, y se les prohíbe terminantemente acercarse a las flores y trepar a los árboles... (Morales, 1927a).
}

Por tanto, Morales defiende la Nueva Escuela y los movimientos de renovación pedagógica que afloran en los años veinte como parte del higienismo y nuevas formas de regeneración y justicia social. Hay una convergencia entre el papel de la mujer, por ejemplo como maestra, y unos nuevos principios sociales que cabe asimilar a la modernidad.

La defensa de la escuela de calidad la llevará a dedicar un artículo a la petición expresa de unas mejores instalaciones para la Escuela Modelo, un colegio de chicas por el que interpela directamente al Ayuntamiento de Barcelona (Morales, 1929). Todavía fue más lejos. Se implicó en la iniciativa de abrir una Residencia de Señori- 
tas, a imagen de la madrileña creada por María de Maeztu, para chicas jóvenes que tenían que vivir en Barcelona para estudiar o que comenzaban a trabajar, y necesitaban de un espacio sin los considerados riesgos para las mujeres en las pensiones de entonces. El proyecto se realizó en 1931, como anunciaba ella misma desde las páginas de La Vanguardia: "De aquí a muy poco las estudiantes (...) que vengan (...) a Barcelona tendrán su 'Residencia'" (Morales, 1931). La directora de la Residencia Internacional de Señoritas Estudiantes de la Generalitat de Catalunya, situada en el palacio de Pedralbes, fue, desde su fundación, la propia María Luz Morales.

En su papel en la prensa, por tanto, hay indicios claros de activismo y regeneración social cuando se trataba de reivindicar un espacio adecuado para el progreso y el bienestar de las mujeres. Una idea que comparte con el feminismo conservador (Scanlon, 1986: 200-212) pero no con el católico (Blasco, 2006). Cercana a las posturas feministas que en Barcelona representa cierta burguesía ilustrada con la que conectó durante su formación, como las ideas de Dolors Monserdà o Carme Karr, Morales rechaza el papel agitador del sufragismo inglés, igual que lo hizo buena parte del feminismo español previo a la Segunda República (Franco, 2004: 458-459). Evitaba considerarse feminista, por mucho que defendiera el trabajo de las mujeres lejos del hogar incluso con un exacerbado optimismo.

...de repente, cambia el panorama por completo. Ábranse de par en par a las mujeres las puertas de despachos y oficinas. No se les niega el derecho a ningún trabajo decoroso. En Academias, Institutos y Universidades las muchachas de hoy encuentran, al alcance de la mano, cultura y respeto. De empleadas van, las que lo merecen, convirtiéndose en jefes. Un sueldo de mil pesetas mensuales empieza ya a no ser un sueño de las Mil y Una Noches para mujer que posea capacidad, laboriosidad e iniciativa. En letras y en artes triunfa un buen puñado de claras mujeres. Las profesiones liberales, ipor tan largo tiempo vanamente anheladas!, dejan sus puertas entreabiertas para que cedan al empuje suave de las que quieran y puedan adentrarse por ellas. En Bibliotecas y Ateneos la presencia de las mujeres es ya cosa tan corriente y natural como la del hombre. Y todo esto rápida, casi velozmente (Morales, 1927b).

El texto rebosa euforia, como si el mundo hubiera renacido en una esplendorosa modernidad y miles de mujeres hubieran encontrado en los últimos tiempos el trabajo decoroso que tanto habían deseado. Incluso empiezan a ascender en la jerarquía laboral, nos advierte Morales, que se atreve a poner una cantidad al sueldo que pueden llegar a alcanzar estas nuevas trabajadores de la cultura, unas mil pesetas mensuales, dice, un sueldo extremadamente alto que algún director de diario, en realidad, no cobraba en esos tiempos ni por dirigir dos publicaciones a la vez. ${ }^{6}$

6 Manuel Llanas (1998: 98) compara el magnífico sueldo de Agustín Calvet en La Vanguardia, cinco mil pesetas, con las ochocientas pesetas que cobraba en 1933 el director de L'Opinió i La Rambla, Joaquim Ventalló, por la dirección de las dos publicaciones. Si tenemos en cuenta que el artículo de María Luz Morales se escribió en 1927, seis años antes, no parece razonable que cualquier mujer profesional pudiese cobrar en ese momento las mil pesetas mensuales a las que alude la periodista. 
María Luz Morales se refiere, por supuesto, a un pequeño reducto de mujeres ilustradas y de profesiones liberales que habían encontrado algunas oportunidades. Ella misma era una asidua del Ateneu Barcelonès, donde se la podía ver a menudo trabajando. Sin embargo, el empeño y el optimismo que la embargan la lleva a exagerar una tendencia que desde luego existía, como su mismo caso demuestra, pero que no se podía ni mucho menos generalizar a "las muchachas de hoy", ya que la inmensa mayoría de las niñas no tenía ni acceso regular a una educación completa. Era cierto que proliferaban y se anunciaban en la prensa academias para la formación de secretarias. Ofrecían cursos de dactilografía o comercio, por ejemplo, y ya hemos hecho referencia a la importancia del Instituto para la Mujer, al que ella misma asistió como alumna, pero el tono parece exaltado para una realidad en la que el analfabetismo femenino llegaba a un 47,5\% de las mujeres a principio de los años treinta (Altés, 2007: 28).

La escritora reconoce el pasado oscuro y difícil que han atravesado las mujeres, y liga los nuevos tiempos al abandono del feminismo reivindicativo.

... al fin, las mujeres han descendido de la alta torre del feminismo agresivo, y, dejando a un lado exigencias, insultos, teorías absurdas y paradojas disolventes, han venido a mezclarse con la multitud, a vivir vida humana, tomando parte en la lucha, no en único provecho de sus egoístas intereses, sino, conjuntamente con los hombres, en defensa de los de la humanidad (Morales, 1927b).

Se trata pues de tener la valentía de cambiar el papel social de las mujeres y reclamar la necesidad de acceder libremente a la educación, a la cultura y al espacio público, valores que se intuían en esos tiempos de profundos cambios sociales y que se podrían clasificar como propios del republicanismo, pero siempre que se confirme una feminidad cuya esencia es, antes que nada, darse. Se fragua en Morales lo que se ha llamado un modelo de "Nueva Mujer" en las facetas política y cívica, unos fenómenos de feminidad que implican una ruptura individual, fenómenos que serán minoritarios y a veces llamativos, y que mostraron en el primer tercio del siglo XX que en ciertas condiciones se podía romper con el pasado (Ramos, 2014: 41) siempre que se evitasen las veleidades revolucionarias:

Estas mujercitas que creen hoy sonada su hora, han substituido exigencia por merecimiento. Antes de pedir... han dado. Así en la pasada guerra su abnegación, así en oficinas y despachos su trabajo, su puntualidad, su eficacia, así en Institutos y Universidades su inteligencia, y en artes y letras y carreras liberales su fino talento. Y aún más. Están poniendo en la vida de todos la nota femenina, tierna, maternal, que en el mundo de los hombres solos faltaba. Ateniéndonos únicamente a entidades femeninas ya citadas, bástenos recordar las "Casas de los Niños" que está levantando el "Lyceum Club", de Madrid, y la reforma de las Inclusas y Casas de Maternidad de la que el "Comité Femenino de Mejoras Sociales", de Barcelona, se ocupa activa y enérgicamente (Morales, 1927b).

Por tanto, la ocupación del espacio público por parte de la mujer se basa, por un lado, en unas capacidades que no se pueden negar y una actitud regeneracionis- 
ta, pero, a la vez, en una esencia femenina que tiene que ver con la entrega y la devoción, una postura claramente conservadora.

Esta es la magnificencia de las grandes mujeres: capacidad y entrega. No habría mejor ejemplo que el impacto que dejó en su memoria Marie Curie, a quien conoció en la visita que esta hizo a Madrid en abril de 1931, acompañada de su hija Eva. A propósito de la muerte de Curie, Morales, quien fue su "cicerone en alguno de aquellos días de abril", recuerda los momentos que pasaron juntas y las impresiones y la actitud de la científica, en especial cuando le enseñaron la Casa del Labrador, en Aranjuez. Resulta significativa una de sus afirmaciones sobre la célebre mujer: "No (...) le gustaba que le hicieran preguntas _ iciertamente bien ociosas, cuando es toda una vida la que habla! - acerca de sus opiniones sobre feminismo" (Morales, 1934). Esta misma observación podría aplicarse a quien la suscribe.

Morales tampoco aceptará nunca que el hombre y la mujer sean iguales. Cada cual tiene un ser, si no intangible, de difícil definición, y ninguno de los dos debe salir de sí mismo para intentar ser el otro. Pero los dos tienen el mismo valor social. Y la misma necesidad de existencia pública. Por eso se alegra de que las mujeres puedan votar en las elecciones legislativas de noviembre de 1933, y le pone cierto humor a lo que llama el "pánico masculino" frente a la novedad.

Los hombres — ¡ criaturas pusilánimes! — son los más asustados. Y es curioso que cada uno da por segura la ventaja del voto femenino... para su contrario. Lo que quiere decir que cada uno - y todos- no está muy seguro de las electoras de su lado. Lo de siempre, al fin. Una mujer: un enigma. ¿Qué no serán trescientas trece mil cuarenta y dos mujeres? Ninguno agradece el refuerzo (Morales, 1933a).

La periodista visita las divisiones femeninas de todos los partidos que se presentan a las elecciones para constatar hasta qué punto callan las mujeres, todavía más que los hombres. Pregunta por tácticas, por la cantidad de miembros que tienen las agrupaciones femeninas y si organizan actos electorales propios o mezcladas con los hombres. Obtiene como respuestas vaguedades e imprecisiones. Explica a su vez aquello que supuestamente oye en la calle, si los hombres convencerán a sus mujeres y las arrastrarán a votar lo mismo que ellos, o si más bien ocurrirá lo contrario, dos posturas irreconciliables. Ya en la tercera entrega de la serie, María Luz Morales reclama la independencia de algunas mujeres que, voten lo que voten, lo hagan por ellas mismas, de la misma forma que llevan contribuyendo al bien general en multitud de pequeños actos sociales y culturales por toda la ciudad, referencia que supone una forma nada usual en ella de hablar de sí misma.

Pero el acto de votar no implica la obediencia a un partido, aunque sí deba ser la expresión de unos ideales. Y hay organizaciones femeninas, ajenas a la política, y no por ello menos coherentes y organizadas. Agrupaciones de mujeres reunidas — son ejemplospor un ideal feminista, o por la fe, o por una cooperación en la beneficencia... Hay en Barcelona, en lo social, una Acción Femenina, un Comité Femenino de Mejoras Sociales [en el que ella misma participaba], un Sindicato Profesional de Obreras, que también 
harán su peso. Ya no digamos la Cívica Femenina, la Orientación Católica para señoritas oficinistas, y otras agrupaciones confesionales que cuentan con muchos miles de asociadas (Morales, 1933b).

No se queda solo aquí, sino que además anima a las mujeres al voto precisamente para ser mejores que los hombres:

La tónica general que, por días, por momentos crece, es el sentimiento de la responsabilidad, y —sobre todo— el entusiasmo. ¿Irán las mujeres a dar una lección de civismo a los muchos miles de hombres que, durante años, se quedan en casa los días de elecciones? (Morales, 1933b).

\section{CONCLUSIONES}

Como se ha podido advertir, es posible extraer de los artículos de María Luz Morales en La Vanguardia una visión clara de la feminidad que sobrepasa con mucho la intención de comentar acontecimientos culturales. No se aprecia en Morales una voluntad de polemizar ni alzar la voz en sus textos para reivindicar nada. Ni contra la tradición que hoy llamaríamos patriarcal, ni contra las normas heredadas.

Los comentarios sobre el papel de la mujer en sus artículos en La Vanguardia tienen presente al feminismo reivindicativo, eso sí, aunque sea para utilizar unas armas claramente distintas. Sin embargo, se dan destacadas coincidencias en desear para las mujeres una situación diferente a la heredada y propia de unos tiempos nuevos, una mejora que solo se puede alcanzar a través de la cultura. Su visión de la feminidad se plasmó en su forma de vivir y en muchas de sus elecciones personales, y puede calificarse como un feminismo conservador y republicano, marcado por una visión reflexiva e intelectual de la realidad social. Criticó el feminismo que ella llamó "agresivo", es decir, el revolucionario porque se centraba más en exigir que en colaborar. Defendió con rotundidad el derecho al voto y al trabajo remunerado fuera del hogar, así como la participación pública, cívica y política de cualquier mujer.

Morales invoca a la mujer a formarse y a trabajar no solo en los ámbitos domésticos. Para lograrlo, hay que reformar profundamente la educación y dejarla en manos de la pedagogía profesional. No anima a la mujer a abandonar sus obligaciones tradicionales sino más bien a reinventarlas. No pretende que compita con el hombre, al que no considera tanto un adversario sino más bien un ser distinto, de mecanismos y procesos muy alejados a los femeninos, con el que solo se puede congeniar precisamente dentro del espacio que proporciona el conocimiento, la curiosidad y el saber.

No comparte el agravio por el sufrimiento histórico de la mujer, que no niega, pero no lo utiliza como una razón para trazar reivindicaciones radicales. La mujer no tiene ninguna necesidad de pretender llevar a cabo los trabajos masculinos. Sería traicionar su propia esencia. Llegar a describir dicha esencia ha sido una tarea antigua de literatos y filósofos que, salvo en contadas excepciones, suele 
fracasar porque atañe más bien a la poesía que a la prosa, a lo intangible que al raciocinio.

María Luz Morales fue una mujer discreta, católica y reflexiva que salió del hogar y mantuvo una intensa vida social y laboral. No solo lo hizo ella misma, sino que lo defendió en los escritos analizados: participar en comités y grupos de interés social. Formar parte de agrupaciones, ateneos, juntas directivas e iniciativas sociales, y no solo por un impulso mundano que cada vez tenía más presencia en la sociedad, sino por dedicación, por solidaridad con otras mujeres en una propuesta que tenía elementos de defensa común y de ayuda mutua.

Propugnó, por tanto, la visibilidad de la mujer, la ocupación del espacio público. Una función social que tenía que ver con los principios de regeneración y mejora colectiva que la acercaban a los principios republicanos. De hecho, aunque tuvo mucho cuidado de no entrar en cuestiones partidistas, no pareció preocuparle la instauración de la Segunda República, a diferencia de otros colaboradores de La Vanguardia. No opinaba de política porque la considerara una especie de actividad masculina, como otras muchas. Pero cuando opinó sobre propuestas pedagógicas, muchas de las iniciativas que impulsó fueron asumidas por la Escuela Nueva.

Morales aprovechaba los espacios de colaboración entre mujeres, de grandes posibilidades, para mejorar la vida colectiva. Era el signo de los tiempos, una especie de revolución que no tenía que ser ni silenciosa ni discreta y que llevó a las mujeres a ocuparse de determinados trabajos y a mantener una posición social visible y clara basada en la educación y en la capacitación profesional, una forma de mirar al género masculino a su misma altura.

Naturalmente, esos tiempos nuevos estaban a punto de desaparecer. Otros estudios tendrán que plantearse cómo cambia — si lo hace- la visión de la feminidad de María Luz Morales a partir de la guerra civil, además de profundizar en los problemas que sufrió ella misma cuando fue apartada de su trabajo en La Vanguardia en mayo de 1939, procesada unos meses después y encarcelada durante unas semanas en 1940. Cómo influyó semejante cataclismo personal y colectivo en sus ideas.

Francesc Salgado de Dios (francesc.salgado@ upf.edu) es licenciado en Filosofía y Ciencias de la Educación y licenciado y doctor en Periodismo. Es profesor de la Universitat Pompeu Fabra desde 2006 y miembro del Grup de Recerca en Periodisme (GRP). Sus líneas de investigación abarcan la historia de la información en la segunda mitad del siglo XX y la deonto- logía. Además de publicar diversos artículos, se ha encargado de la edición de algunos libros, entre los que se encuentran El periodismo en las transiciones políticas. De la Revolución Portuguesa y la Transición Española a la Primavera Árabe o la antología en tres volúmenes de la obra periodística de Manuel Vázquez Montalbán, tema al que dedicó su tesis doctoral (2009). 


\section{Bibliografía}

Altés, E. (2007). Les periodistes en el temps de la República. Barcelona: Col-legi de Periodistes.

Blasco, I. (2006). "Feminismo católico". En: Morant, I. (Dir.) Historia de las mujeres en España y América Latina. Del siglo XX a los umbrales del XXI. Vol. 4. Madrid: Cátedra, pp. 55-75.

Cabré, M. Á. (2017). María Luz Morales, pionera del periodismo. Barcelona: Libros de Vanguardia.

Casasús, J. M. (1988). Iniciación a la periodística. Barcelona: Teide.

Fabre, J. (2017). Periodistes, malgrat tot. La dificultat d'informar sota el franquisme a Barcelona (1939-1966). Barcelona: Ajuntament de Barcelona.

Favà, M. L. (1975). 50 mujeres de nuestro tiempo: cómo y por qué han llegado a ser famosas. Barcelona: Diàfora.

Franco, G. A. (2004). "Los orígenes del sufragismo en España". Espacio, Tiempo y Forma. Serie V, $H^{a}$ Contemporánea, 16, pp. 455-482.

Calvet, A. (Gaziel) (1994). Història de 'La Vanguardia' i nou articles sobre periodisme. Barcelona: Empúries.

Gómez Mompart, J. L. (1992). La gènesi de la premsa de masses a Catalunya (1902-1923). Barcelona: Pòrtic.

Guillamet, J. (1994). Història de la premsa, la ràdio i la televisió a Catalunya (1641-1994). Barcelona: La Campana.Huertas, J. M. (2006). Una història de 'La Vanguardia'. Barcelona: Angle. temporáneo español, con especial atención al exilio teatral republicano de 1939, así como los estudios del exilio y las escrituras del yo. Ha publicado varios trabajos en obras colectivas y en revistas especializadas como $\mathrm{El}$ Correo de Euclides, Laberintos, Anales de la Literatura Española Contemporánea, Ínsula, Forma o Primer Acto.
Julio, T. (2017). "María Luz Morales, traductora: estado de la cuestión y perspectivas de investigación". Confluenze, 9-2 (diciembre), pp. 55-68.

Llanas, M. (1998). Gaziel: vida, periodisme $i$ literatura. Barcelona: Publicacions de l'Abadia de Montserrat.

Mariné, C. P. (1920). "Revista de la moda". El Hogar y la Moda, 30 de mayo, p. 3.

Morales, M. L. (1921). "La eterna lamparita". La Vanguardia, 21 de octubre, p. 10.

-. (1922). "Los cuentos". La Vanguardia, 7 de marzo, p. 16

—. (1923). "Molière y las mujeres". La Vanguardia, 3 de enero, p. 11.

—. (1924). "El lord romántico". La Vanguardia, 1 de mayo, pp. 5-6.

-. (1927a). "El poeta de la madre y del niño". La Vanguardia, 22 de enero, pp. 10-11.

-. (1927b). "La hora". La Vanguardia, 25 de mayo, p. 5.

—.(1929). "Escuela 'Modelo'". La Vanguardia, 2 de diciembre, pp. 7-8.

-. (1931). "Residencia - Hogar". La Vanguardia, 19 de agosto, pp. 5-6.

-. (1933a). "La incógnita del voto femenino". La Vanguardia, 25 de octubre, p. 5.

-. (1933b). "Ecos del salón y la calle". La Vanguardia, 27 de octubre, p. 6.

-. (1934). "La eterna presencia". La Vanguardia, 13 de julio, p. 3. 
Nadal, S. (1974). "Periodista de cuerpo entero". La Vanguardia, 7 de marzo, p. 49.

Pericay, X. (2010). "Paulino Masip, director de La Vanguardia". Trípodos, 27, pp. 125139.

Ramos, M. D. (2014) "La construcción cultural de la feminidad en España: desde el fin del siglo XX a los locos y politizados años veinte y treinta". En: Nash, M. (ed.) Feminidades y masculinidades. Arquetipos y prácticas de género. Barcelona: Alianza, pp. 21-46.

Rodrigo, A. (1979) Mujeres de España (Las silenciadas). Barcelona: Plaza \& Janés.

Sariol Badia, J. (1977) Petita història de la guerra civil. Vint-i-tres testimonis informen. Barcelona: Dopesa.

Scanlon, G. M. (1986) La polémica feminista en la España contemporánea (1868-1974). Madrid: Akal.
Segura, I. y Selva, M. (1984) Revistes de dones (1846-1935). Barcelona: Edhasa.

Servén, C. (2013) "Literatura, periodismo y cine. María Luz Morales en La Vanguardia". En: Servén, C. y Rota, I. (eds.) Escritoras españolas en los medios de prensa. 1868-1936. Sevilla: Renacimiento, pp. 267-289.

Tarín, J. (1973). "Prólogo". En Morales, M. L. Alguien a quien conocí. Barcelona: Juventud, pp. 5-7.

Van Dijk, T. A. (1996) "Opiniones e ideologías en la prensa". Voces y Culturas. Revista de Comunicación, 10-II semestre, pp. 9-50.

Wodak, R. y Meyer, M. (ed.) (2003). Métodos de análisis crítico del discurso. Barcelona: Gedisa. 
